\title{
Artificial artificial intelligence: Surgeon intuition and computers to predict graft patency
}

Francis Duhaylongsod, MD

See related article on page 468 .
From Cardiothoracic and Vascular Surgery Services, Medical Center Hospital, Odessa, Tex.

Received for publication April 28, 2006; accepted for publication May 2, 2006.

Address for reprints: Francis Duhaylongsod, MD, 750 W. 5th St., Odessa, TX 79763 (E-mail: duhay001@aol.com).

J Thorac Cardiovasc Surg 2006;132:466-7

$0022-5223 / \$ 32.00$

Copyright (๑) 2006 by The American Association for Thoracic Surgery

doi:10.1016/j.jtcvs.2006.05.016
$\mathrm{D}$ i Giammarco and colleagues ${ }^{1}$ report in this issue a retrospective evaluation of intraoperative measurement of transit-time flow (TTF) to predict postoperative coronary artery bypass graft failure. During a 6-year period, 157 patients had both intraoperative TTF measurement and postoperative control angiography done within 1 year of coronary artery bypass grafting. After a mean follow-up of $6.7 \pm 4.8$ months, 266 grafts were patent (87.5\%). Meaningful differences were observed between patent and obstructed grafts in maximum flow, mean flow $\left(\dot{\mathrm{Q}}_{\text {mean }}\right)$, percentage of patients with $\dot{\mathrm{Q}}_{\text {mean }}$ $15 \mathrm{~mL} / \mathrm{min}$ or less, pulsatility index (PI), percentage of patients with PI at least 3.0 , percentage of backward flow $(\% \mathrm{BF})$, and percentage of patients with $\% \mathrm{BF}$ at least $3.0 \%$. Moreover, multiple logistic regression analysis revealed that $\dot{\mathrm{Q}}_{\text {mean }} 15 \mathrm{~mL} / \mathrm{min}$ or less, PI at least 3.0, and \%BF at least $3.0 \%$ were independent predictors of graft failure. Di Giammarco and colleagues concluded that the combination of $\dot{\mathrm{Q}}_{\text {mean }} 15 \mathrm{~mL} / \mathrm{min}$ or less, PI at least 3.0, and $\% \mathrm{BF}$ at least $3.0 \%$ may predict graft failure within 1 year after coronary artery bypass grafting.

From this study and the body of literature on which it was based emerge two major points. First, a wealth of information can be gleaned from graft flow waveforms (exclusive of $\dot{\mathrm{Q}}_{\text {mean }}$ ) that may be important in predicting graft patency. Second, although retrospective studies of this sort are inherently biased, cost-benefit and risk-benefit considerations preclude a sufficiently powered prospective study relating flow measurements to graft patency from ever being completed. Consequently, how should studies like this be interpreted, and are its recommendations relevant to clinical practice?

Any clinical study that incorporates control angiography, whether to evaluate a new technique (such as off-pump grafting or anastomotic nitinol clips) or a new diagnostic tool (such as TTF), suffers from inefficient patient accrual. Indeed, of 3567 patients treated by Di Giammarco and colleagues during the study period, only 157 patients (4\%) underwent both TTF and control angiography. Of these, $72(46 \%)$ underwent angiography for symptoms of angina. Clearly, symptom-driven angiography is likely to bias graft patency results negatively. Accordingly, the study sample may represent predominantly patients predicted to have worse graft patency. Given the uncertain relationship between $\dot{Q}_{\text {mean }}$ measured intraoperatively and long-term graft patency, most surgeons use graft blood flow measurements either selectively or not at all. Indeed, surgeons who routinely document graft flow measurements in the operative record often tout its value from a medicolegal perspective rather than on the basis of scientific evidence. To my knowledge, this advantage is more perceived than real. In practice, TTF measurements can be useful as an adjunct in situations where graft or anastomotic quality is at risk for early failure - that is, in cases involving a small-caliber artery, poor distal runoff, or an endarterectomized vessel, or when the surgeon harbors concerns about graft tension, quality, or tortuosity. These are patients predicted to have worse graft patency, a subset similar to that examined by Di Giammarco and colleagues.

In summary, although surgeons should not feel compelled to revise all graft anastomosis solely on the basis of the criteria proposed by Di Giammarco and colleagues, TTF measurement may prove useful as an adjunct in cases where a high 
index of suspicion for early graft failure clearly exists. In the meantime, the allure of a noninvasive, accurate, and reproducible means to relate coronary graft flow to intermediateor long-term graft patency is irresistible, and contributions such as this study help to advance this goal.

\section{Reference}

1. Di Giammarco G, et al. Predictive value of intraoperative transit-time flow measurement for short-term graft patency in coronary surgery. J Thorac Cardiovasc Surg. 2006;132:468-74. 